\title{
APPLICATION OF ARTIFICIAL NEURAL NETWORK FOR BLAST PERFORMANCE EVALUATION
}

\author{
Ratnesh Trivedi $^{1}$, T.N.Singh ${ }^{2}$, Keshav Mudgal ${ }^{3}$, Neel Gupta ${ }^{4}$ \\ ${ }^{1}$ Senior Scientist, CSIR-Central Institute of Mining and Fuel Research, Dhanbad \\ ${ }^{2}$ Professor, Department of Earth Sciences, Indian Institute of Technology Mumbai, Powai, Mumbai,India \\ ${ }^{3}$ Student, B.Tech (Mining), Indian School of Mines, Dhanbad \\ ${ }^{4}$ Student, M.Tech Dual Degree(Mining), Indian School of Mines, Dhanbad
}

\begin{abstract}
Despite of technological advancement in the field of rock breakage, blasting is still an economical means of rock excavation for mining or civil engineering projects. Blasting has some environmental as well as societal side effects such as ground vibrations, air blasts, noises, back breaks, fly rocks, dusts and, of course, annoyance of inhabitants living surrounding the mining areas. Recent developments in the field of blasting techniques can minimize such ill effects by optimizing rock friendly explosive and blast design parameters. The purpose of this paper is to present the techniques, advances, problems and likely direction of future developments in exploring the applications of Artificial Neural Networks (ANN) in rock fragmentation by blasting and its significance in minimizing side effects to environment in particular and society at large. Many researchers have found the back-propagation algorithm in ANN is especially capable of solving predictive problems in rock blasting. ANN has been successfully applied in predicting, controlling, assessing impact of blast design parameters, ground vibrations, air blasts, back breaks etc. in mines. ANN needs to be applied in certain grey areas like predicting and controlling fly rock hazards in opencast mines, blast induced dust, blasting in jointed rockmass etc.
\end{abstract}

Keywords: Artificial Neural Networks; Blasting; Mining; Rock Fragmentation; Ground Vibrations; Airblasts; Flyrocks.

\section{INTRODUCTION}

Drilling and blasting combination is still a cheapest method of rock breakage and in mining as well as in civil construction works. Blasting, fragments the rock into pieces that are suitable for crushing (Lawrence et al., 2002) or further processing and is still the most commonly applied method. Rock fragmentation has been the concern of many research works because it is considered as the most important aspect of production blasting, since it affects on the costs of drilling, blasting and the efficiency of all the subsystems such as loading, hauling and crushing in mining operations, Farmarzi et al.(2013). When an explosive detonates in a blast hole, instantaneously huge amount of energy in forms of pressure and temperature liberates around the hole. Though significant developments have taken place in explosive technology, the explosive energy utilization has not made much progress due to complexity of various rock parameters (Cheng and Huang, 2000; ISRM, 1992; McKenzie, 1990). Only a small proportion of the total energy is utilized for actual breakage and displacement of rock mass and the rest of the energy gets spent in undesirable side effects like ground vibrations, air blasts, noises, back breaks, flyrocks, dusts etc. (Bajpayee et al., 2004; Hagan , 1973; Singh et al., 1994a; Wiss and Linehan, 1978), which may further cause annoyance of the people living surrounding the mining areas (Raina et al., 2004).

Although, these negative effects can not be eliminated completely yet can be minimized up to an extent of permissible limits to avoid damage to the surrounding environment and the existing structures (Singh et al., 1994a; Wiss and Linehan, 1978). A study (Raina et al., 2004) of the human response to blasting in mining localities across India has shown that the response is not simply socio-political, as frequently assumed. It has been reported that, irrespective of those questioned; a basic concern for the safety of property was the main response.

Initiation of the explosive in blast hole converts chemical energy into a huge volume of gases and fumes. Thereby, intense dynamic stresses gets set up around the blast hole due to sudden acceleration of the rockmass by detonating gas pressure on side wall. The strain waves get transmitted in to the surrounding rockmass and generate a wave motion (Wharton et al., 2000). These strain waves carry strain energy that is responsible for the fragmentation of the rockmass by means of breakage mechanism such as crushing, radial cracking, and reflection breakage in the presence of a free face. The crushed zone and radial fracture zone encompass a volume of permanently deformed rock. Thereafter, the strain 
wave intensity diminishes and causes no permanent deformation in the rockmass. The strain waves propagate through the medium as the elastic waves. The waves in an elastic zone are characterised by the peak velocity of the rock particles through which they propagate and their behaviour is essentially visco-elastic (Hagan, 1983).

The development of empirical relationship within the parameters for a given system can be useful for prediction. However, the laws underlying the behavior of a system are not easily understood and the empirical regularities are not always evident and can often be masked by environmental hazards. That's why, now a days, more precise techniques like Artificial Neural Networks (ANNs), Maximum Likelihood Classification (MLC), Genetic Algorithm (GA), Technique for Order Preference Similarity to Ideal Solution(TOPSIS), etc. are frequently applied (Monjezi et al., 2007; Tawadrous , 2006).

The general difficulty in modelling of rock masses by numerical methods is that rock is a natural material, and so the physical or engineering properties have to be established and the rock mass is largely discontinuous, anisotropic, inhomogeneous and non-elastic (Harrison and Hudson ,2000). This problem can be overcome at some extent in neural networks as the geometrical and physical constraints of the problem that appear in governing equations and constitutive laws, when the numerical modeling techniques are used, are no longer so dominating in neural networks (Jing, 2003).

\section{ANN ARCHITECTURE IN BLASTING PROBLEMS}

ANN technique is relatively a new branch of the 'artificial intelligence' (AI) and has been developed since the 1980s (Grossber, 1991; Hertz et al., 1990; Rumelhart and McClelland, 1986). The ANN technique is considered to be one of the widely used intelligent tools for simulating complex problems. The ANN is information -processing system simulating structures and functions of human brain (Simpson, 1990). A neural network can be considered as an intelligent hub since it is able to predict an output pattern on the basis of previous learning. After completion of proper training, neural networks can detect similarities when presented a new pattern and accordingly, result a predicted output pattern. This property gives excellent interpolation capability to the technique, especially when input data is noisy. This technique has the ability of generalizing a solution from the pattern presented to it during the training.

The development of a neural network can be broadly classified into three steps: defining the network architecture, training and testing (Freeman and Skapura, 2002). A neural network must be trained and tested before interpreting new information. The neural network is first trained by processing a large number of datasets. A number of algorithms are available for training the artificial neural networks, among all the available algorithms the back-propagation algorithm developed by Werbos (1974) is widely applied in different field of science and engineering because it is the most versatile and robust technique. The algorithm based on Levenberg-Marquardt approximation method is more powerful than commonly used gradient descent methods. Levenberg-Marquardt approximation makes training more accurate and faster near minima on the error surface (Demuth and Beale, 1994).

The back-propagation algorithm is especially capable of solving predictive problems (Huang and Wfinstedt, 1998; Tawadrous and Katsabanis, 2006). The feed forward backpropagation neural network (BPNN) always consists of at least three layers; input layer, hidden layer and output layer (Neaupane and Adhikari, 2006). Each layer consists of a number of elementary processing units, called neurons, which are connected to the next layer through weights, i.e. each neuron in the input layer will send its output (as in put) for neurons in the hidden layer and similar is the connection between hidden and output layer. The number of hidden layers and the number of neurons in the hidden layers change according to the problem to be solved.

The connection strengths, also called network weights, are adjusted in such a way that the network's output matches a desired response (Lippman, 1987). In the back propagation training, the connection weights are adjusted to reduce the output error (Tawadrous, 2006). For example, in the back propagation network, the goal of learning is to minimize the error between the desired outputs (target) and the actual outputs of the network.

Artificial neural networks are highly distributed interconnections of adaptive non-linear processing elements. The back propagation neural network is constructed in such a way that each layer is fully connected to the next layer. In other words, every neuron in the input layer will send its output to every neuron in the hidden layers, and every neuron in the hidden layers will send its output to every neuron in the output layer. The numbers of neurons in the input layers are equal to numbers of input variable selected for the problem to be solved (Grznar et al., 2007; Huang and Wfinstedt, 1998). Feed-forward back-propagation neural network is a strong technique of modeling for input/output pattern identification problems ( Monjezi et al., 2011 ). A three-layer feed-forward back-propagation neural network with 2-5-1 architecture was trained and tested using 130 experimental and monitored blast records from the surface coal mines of Singareni Collieries Company Limited, Kothagudem, Andhra Pradesh, India to evaluate and predict the blast induced vibrations. (Khandelwal et al. 2011) 
Once the neural network has been successfully trained with sufficient number of sample data sets, it is tested for a few datasets whose output is already known. After validation of a neural network, it can be used for predictions of output parameter for the corresponding input parameters based on its previous learning of the similar patterns (Singh, 2004). Researchers in rock science and engineering are mostly using multi-layer back propagation neural networks with one hidden layer (Khandelwal and Singh, 2002; 2006; Singh and Singh, 2005; Sawmliana et al., 2007) or two hidden layers (Jing and Hudson, 2002; Lu, 2005;Monjezi et al., 2008; Singh et al., 2005) in addition to input and output layers depending on the problem under study. Neural network like multi-layer perceptron (MLP), radial basis function (RBF), and many others are also used. (Haykin, 1994; Rai et al., 2004).

Jing and Hudson (2002) outlined the various advantages and disadvantages of neural networks. The advantages of neural networks are that (1) The geometrical and physical constraints of the problem, which dominate the governing equations and constitutive laws are not such a problem. (2) Different kinds of neural networks can be applied to a problem. (3) There is the possibility that the 'perception', we enjoy with the human brain, may be mimicked in the neural network, so that the programs can incorporate judgments on the basis of learning and experiences. The drawback of neural networks is super complicated curve fitting either over-fitting or under-fitting (Jing, 2003). To formulate the network for any specific problem, super complicated curve fitting occurs mainly due to training of network with too many epochs. A strategy developed to avoid over-fitting or under-fitting is to investigate the goodness of prediction using different types of network architecture and select the network with minimum root mean square error (Hornik, 1991) and with the application of Bayesian regulation (MacKay, 1992) while constructing neural network. Again, neural networks with the higher number of input variables have better predictability (Mohamed, 2009).

The artificial intelligent method of simulating and predicting blasting is accurate, reliable, practical, user oriented, and easy to operate as well as useful for engineers (Lianjon et al., 2002). Neural network models provide descriptive and predictive capabilities and, for this reason, have been applied through the range of rock parameter identification and engineering activities (Hudson and Hudson, 1997).

As ANN is multidisciplinary in nature, it is being successfully used in many industrial areas as well as in research areas. Singh et al. (2001) have predicted the strength properties of schistose rocks by neural network. The stability of waste dump from dump slope angle and dump height is investigated by Khandelwal and Singh (2002). They found very realistic results as compared to the other analytical approach. Yang and Zhang (1997a) have carried out the point load tests and analyzed using ANN. Cai and Zhao (1997) have discussed about tunnel design and optimal selection of the rock support measure to ensure the stability of the tunnel using neural networks. Maulenkamp and Grima (1999) have predicted uniaxial compressive strength using neural networks. ANN technique has been used for determining event types such as earthquake, blasting in mines, chemical explosions, etc. from seismological data by (Dysart and Pulli,1990; Finnie, 1999; Musil and Plensiger, 1996; Rudajev and Ciz, 1999). Neaupane and Achet (2004) used back propagation neural network for landslide monitoring in higher Himalayan region. Many other researchers have also used this technique for the prediction of various complex parameters from simple input parameters (Dehghani, 2007; Kim et al., 2001; Kosko, 1994; Yang and Zhang 1997b).

\section{ANN IN GROUND VIBRATIONS}

Blasts, if not properly designed, may result in ground motions of sufficient intensity to damage the nearby structures. Ground Vibration is a seismic wave that spread out from the blast hole when detonated in a confined manner Khandelwal, (2012). Among all the ill effects of blasting, ground vibration is major concern to the planners, designers and environmentalists (Hagan, 1973). The prediction and control of blast-induced ground vibration has been a subject of interest of researchers for the last few decades (Ambraseys and Hendron, 1968; Dowding, 1996; Duvall and Fogleson, 1962; Indian Standard, 1973; Langefors, Kihlstrom, Westerberg, 1958; Pal Roy, 1993; Wiss and Linehan, 1978, Khandelwal, 2012, Jahed et al. 2013, Duan et al. 2010, Monjezi et al. (2013), Gorgulu et al. $(2013$,$) . The intensity of the blast-induced ground vibration is$ affected by parameters such as the physical and mechanical properties of the rock mass, characteristics of the explosive, and the blasting design ( Gorgulu et al. 2013, Singh, Singh, and Goyal, 1994). The surrounding rock types have moderate influence on ground vibration as compared to blast design (Wiss and Linehan, 1978). Geological discontinuity also plays a significant role in the transmission of ground vibration (Fourney et al., 1993; Singh and Sastry, 1986).

The ground vibration is measured by the peak particle velocity (PPV). A number of empirical formulae and relationships exist for the prediction of PPV as a function of the scaled distance for given geological site conditions (Ambraseys and Hendron, 1968; Duvall and Fogleson, 1962; Gupta, Pal Roy, and Singh, 1987; Hendron, 1977; Indian Standard, 1973; Langefors U and Kihlstrom, 1978; McMahon, 1993; Murrell and Joachim, 1996; Wiss, 1981, M. Monjezi et al. 2011). As the stress wave properties are affected by many inherent variables taking part in such a complex physical process, namely the charge density, the rock mass properties, and the blast geometry, it was observed that the difference of PPV at the same scaled distance from different blast tests could vary by as much as 100 times (Dowding, 1985). Despite of numerous attempts, it is still not possible to develop a predictor relating the intensity of vibration to the large number of blasting parameters 
characterizing for a given situation e.g. hole diameter and depth, number of holes blasted, spacing, burden, stemming column height, quantity of explosive blasted per delay, and horizontal and radial distance from the blast (Singh, 1995b; 2004).

M. Monjezi et al. (2011) developed a model to predict blastinduced ground vibration using artificial neural network (ANN) in the Siahbisheh project, Iran. To construct the model maximum charge per delay, distance from blasting face to the monitoring point, stemming and hole depth are taken as input parameters, whereas, peak particle velocity (PPV) is considered as an output parameter. A database consisting of 182 datasets was collected at different strategic and vulnerable locations in and around the project. From the prepared database, 162 datasets were used for the training and testing of the network, whereas 20 randomly selected datasets were used for the validation of the ANN model. A four layer feedforward back-propagation neural network with topology 4-105-1 was found to be optimum.

Tang et al. (2007) have adopted the back-propagation neural network model to predict the peak velocity of blast vibration. They considered the charge hole diameter, distance, depth, column distance between charge holes, line of least resistance, maximum charge of single hole, maximum charge weight per delay, stemming length, total charge, magnitude of relative altitude and explosive distance as input parameters and found the predicted results from artificial neural network more closer than those from empirical predictors.

Singh (1995a) studied the blast induced ground vibration at Dharapani Magnesite Mine, Pitthoragarh Himalaya in India and predicted PPV using neural networks. Khandelwal and Singh (2006) have underlined the significance of neural network in the prediction of ground vibration and frequency. They used all the possible influencing parameters of rock mass, explosive characteristics and blast design as an input parameters in neural network which was trained by 150 dataset with 458 epochs, tested and verified by 20 new dataset. They found that correlation coefficient determined by ANN was 0.9994 and 0.9868 for peak particle velocity (PPV) and frequency while correlation coefficient by statistical analysis was 0.4971 and 0.0356 .

Chakraborty et al. (2004) have underlined the effectiveness of multilayer perceptron (MLP) networks for estimation of blasting vibration and proposed a fusion network that combines several MLPs and on-line feature selection technique to obtain more reliable and accurate estimation over the empirical predictors. Khandelwal and Singh (2007) have used the three-layer feed-forward back-propagation neural network to predict blast-induced ground vibration level at a magnesite mine in tecto-dynamically vulnerable hilly terrain in Himalayan region in India. They have compared measured \& predicted values of PPV using four widely used ground vibration predictors namely USBM equation (1962), Ambraseys-Hendron equation (1968), Langefors-Kihlstrom equation (1958), and Indian Standard Predictor equation (1973) and found a very poor correlation between measured and predicted PPV values. Again, the same data sets were used to predict PPV values by neural networks and found a better correlation between measured and predicted values.

Mohamed (2009) has used three different models of ANN for prediction the peak particle velocity (PPV) due to blastinduced ground vibrations and observed that the ANN model using a large number of inputs parameters gives better prediction of PPV over the ANN models using single or two inputs parameters. Also, the ANN model with two-input parameters provides better results than the model with one input parameter. That is to say, increase in the number of input variables results in increasing the ability of ANN to learn and to predict more precisely.

Singh and Singh (2005) have studied blast induced ground vibration in Indian opencast mines predicted frequency of ground vibrations. They compared measured values of frequencies with that of predicted values using ANN and multivariate regression analysis and found coefficient of correlation0.905and 0.716 respectively. Singh (2004) have attempted to predict the ground vibration and its frequency in Indian coal measure rocks using artificial neural network and, again they confirmed that the network provided better results than a conventional multivariate regression method.

Peak particle velocity (PPV) is generally used to assess blast vibration damage potential to structures lying on surface but this parameter cannot explain fully the effect on structures such as surface buildings situated far from the point of blasting and which can be damaged even at very low PPVs. Spectral analysis indicates that low frequency ground vibrations $(6-12 \mathrm{~Hz})$ are more damaging than high frequencies (22-80 Hz) (Ramchandar and Singh, 2001; Singh, Singh and Singh, 1994). The longer wavelength and smaller amplitude characteristic of these vibrations damage structures more severely than higher amplitude, shorter wavelength vibrations (Perrson, 1997). Yang and Feng (2004) have identified the response of surface structures when subjected to blast-induced ground vibration near opencast mines using a hybrid evolutionary-neural approach, combining genetic algorithms (GAs) and artificial neural networks and have found an excellent performance of hybrid approach. Maity and Saha (2004) have assessed damage in structures because of variation of static parameters using neural network.

Using ANN, P-wave velocity and anisotropic property of rocks were investigated by Singh et al. (2004a). Yong Lu (2005) has studied the blast induced ground shocks using artificial neural network for underground mines. Singh et al. (2005) have studied the dynamic constants of rockmass with the neural network and neurro-fuzzy system. Singh et al. 
(2004b) have predicted ground vibrations due to blasting with lower error.

\section{ANN IN AIR BLAST}

Air blast is considered to be one of the most detrimental side effects due to generation of noise. Blast induced Air Over Pressure is the energy transmitted through the atmosphere from the blast site in the form of a series of pressure waves. Overpressure simply means the pressure over and above that of atmospheric pressure being present and the term AOP is used to describe the airwave generated by blasting (Oriard, 2002). AOP is generally measured in decibels (dB) using the linear frequency weighting (L). When an explosive gets detonated, transient air blast pressure waves are generated (Wharton et al., 2000) and these transitory phenomena last for a second or so. Unlike blast induced ground vibrations, air blast impacts the house through the roof, walls and windows of the structures and rarely can cause heavy and large scale damage (Kuzu et al., 2009). Besides, it causes annoyance to people living around mining areas and may result in confrontation between the quarry management and those affected (Konya and Walter, 2001; Pal Roy, 2005).

Sometimes, airblast is called as "blast noise". But, the term "blast noise" is misleading because blast noise occurs at a broad range of frequencies and the highest energy blast noise usually occurs at frequencies below that of human hearing $(<20 \mathrm{~Hz})$. Energy above $20 \mathrm{~Hz}$ is perceptible to the human ear as sound, whilst that below $20 \mathrm{~Hz}$ is inaudible, however, it can be sensed in the form of concussion. As its name implies, air blast-overpressure is a measure of the transient pressure changes. Air overpressure is formed either by the direct action of the explosion products from an unconfined explosive in the air or by the direction of a confining material subjected to blast loading (Bhandari, 1997).

A generalized equation has been proposed by many researchers to predict AOP, but due to its site specific nature, it cannot be applicable universally. Khandelwal and Singh (2005) have attempted to predict the air blast using a neural network by incorporating the maximum charge per delay and distance between blast face to monitoring point. They compared the measured values of AOP to those of predicted by ANN, generalised empirical predictor equations and conventional relations and found that the mean absolute percentage of error for ANN was 2.7437 whereas for generalised equation and statistical analysis, it was 8.6957 and 6.9179 respectively.

Sawmliana et al. (2007) have investigated into the most influential parameters affecting AOP such as maximum charge weight per delay, depth of burial of charge, total charge fired in a blast round and distance of measurement and predicted AOP using artificial neural network. The predicted values of AOP by ANN were compared with those predicted by generalised equation incorporating maximum charge weight per delay and distance of measurement. The results obtained from neural network analysis showed that the depth of burial of the charges and maximum charge weight per delay were among the blast designed parameters that have most influence on AOP. The average percentage of prediction error for ANN and generalized equation were $2.05,5.97$ respectively and correlation coefficient were 0.931 and 0.867 respectively. Again it is conformed that the relationship between measured and the predicted values of AOP was found to be more logical in the case of ANN.

Remennikov and Mendis (2006) have underlined the importance of neural network-based model in predicting airblast load in complex environmental configurations such as a dense urban environment or a blast environment behind a blast barrier.

\section{ANN IN FRAGMENTATION ANALYSIS}

Back break can be defined as broken rocks beyond the limits of the rear row of holes in a blast pattern (Jimeno, Jimeno, and Carcedo, 1995). Backbreak is one of the destructive side effects of the blasting operation. Reducing of this event is very important for economic of a mining project, Monjezi et al. (2013) It may cause difficulty in drilling in new benches, having boulder in the next blast, rock fallings, instability of final wall, improper fragmentation etc., and consequently increase the total cost of a mining operation. Konya (2003) believes that back break increases when burden and /or stemming increase. Sari et al., 2013 derived that the stemming length is the most important parameter in controlling backbreak. Gate et al. (2005) have explained that the main reason of back break is insufficient delay timing and /or increasing number of rows in a blast round.

Monjezi et al. (2006a) have predicted the ratio of muck pile before and after the blast, fly rock and total explosive used in the blasting operation using artificial neural networks. These applications demonstrate that neural network models are efficient in solving problems when many parameters influence the process, and when the process is not fully understood. Monjezi et al. (2008) have used the artificial neural network technique to determine the near-optimum blasting pattern so that back break can be minimized and found that the ratio of stemming to burden, the ratio of last row charge to total charge, powder factor, total charge per delay and the number of rows in a blasting round are the major causes of the back break problems. Li et al. (2006) have proposed a coupling system of engineering database and three-layered back propogation neural networks for pre-splitting blasting design. Monjezi et al. (2006b) have estimated burden in tunnel blasting with the use of a multi-layer back propagation neural networks which is used to train and test the developed model to enable prediction of burden. Monjezi et al. (2010) has predicted rock fragmentation in Sarcheshmeh copper mine by 
developing a model using artificial neural network. Zhu and $\mathrm{Wu}$ (2005) have compared the forecasting of blasting fragmentation and by neural networks and correlation. They found that neural network improved the stability of the model.

Karami et al. (2006) have adopted artificial neural networks (ANN) technique in predicting the back break in Gole-Gohar iron ore mine, Kerman, Iran and confirmed the high capability of the neural network in blast designs.

Tawadrou and Katsabani (2005) have underlined the importance of artificial neural networks in the prediction of the geometry of surface blast patterns in limestone quarries. They used 11 input parameters which affect the blast design such as formation dip, blasthole diameter, blasthole inclination, bench height, initiation system, specific gravity of the rock, compressive and tensile strength, Young's modulus, specific energy of the explosive and the average resulting fragmentation size and predicted burden and spacing of the blast. The built model was used to conduct parametric studies to show the effect of blasthole diameter and bench height on geometry of blast pattern.

The muck-pile fragmentation distribution based on blast patterns designed using radial basis function (RBF) of neural network has been predicted by Moghadam et al. (2006). They used blast-hole diameter, number of hole, burden, spacing, depth of hole, stemming, number of rows, velocity of detonation, charge per delay, powder factor, blastability index, water level as Input parameters and the output presented in terms of equivalent screen size that passes $80 \%$ of the blasted materials, equivalent screen size that passes $63.2 \%$ of the blasted materials, and index of uniformity.

Bahrami et al. ( 2011) had developed a model to predict rock fragmentation due to blasting by implementing artificial neural network (ANN) method. In the development of proposed model eight parameters such as hole diameter, burden, powder factor, blastability index etc., were incorporated. Training of model was performed by back propagation algorithem using 220 datasets. A four layer ANN was taken as optimum with architecture 10-9-7-1. Sensitivity analysis revealed that the most effective parameters on rock fragmentation are blastability index, charge per delay, burden, SMR and powder factor.

Using ANN, Jong and Lee (2004) explained influence of geological conditions on the powder factor for tunnel blasting. Leu et al. (1998) analyzed in-depth the influence of powder factors for tunnel blasting. Jong and Lee (2002) predicted powder factor and peak particle velocity in tunnel blasting. Shan et al. (2007) demonstrated tunnel circulation in terms of one-kilogram explosive and one-meter length of blasthole.

\section{ANN IN FLY ROCK HAZARDS}

Flyrock is defined as the rock propelled beyond the blast area by the force of an explosion (IME, 1997). When these rock fragments get thrown beyond the protected area, they result in human injuries, fatalities and structure damages. Flyrock arising from blasting operations is one of the crucial and complex problems in mining industry and its prediction plays an important role in the minimization of related hazards.(Ebrahim Ghaesemi et al. 2012 ).The lack of blast area security and flyrock accounted for $68.2 \%$ accidents in USA (Kecojevic and Radomsky, 2005). An analysis of blasting accidents in Indian mines indicated that more than $40 \%$ of fatal and $20 \%$ of serious accidents were caused by flyrock (Bhandari, 1997). The major causes of flyrock in opencast mines are reduced burden, inadequate stemming length, faulty drilling, backbreak, and loose rock on top of the bench due to poor previous blast, very high explosive concentration, inappropriate delay timing, and their sequence, inaccuracy of delays unfavorable geological conditions such as open joints, weak seams, cavities etc. (Adhikari, 1999; Fletcher and D'Andrea, 1986; Persson, Holmberg, and Lee, 1984; Rehak et al., 2001; Shea and Clark, 1998; Siskind and Kopp, 1995; Workman and Calder, 1994). Any imbalance between the distribution of the explosive energy, geomechanical strength of the surrounding rock mass, and confinement creates a potential hazardous condition by channeling the energy through the path of least resistance. Such imbalance can propel flyrock beyond the protected blast area and create a potential for serious injuries and fatalities (Bajpayee et al., 2004). The results show that the powder factor and charge per delay are the most effective parameters on flyrock distance.

Application of neural networks in predicting and controlling flyrock hazards in opencast mines has not been reported so far. However, an attempt has been made by Monjezi et al. (2007) to control fly rock in blasting operations using TOPSIS method. In recent years, several researches have been done to predict flyrock and ground vibration by means of conventional backpropagation (BP) artificial neural network (ANN), Armaghmi et al., (2013).

Monzei et al. (2013) applied Artificial nueral network (ANN) to predict flyrock in blasting operation of sungun copper mine, Iran. Number of ANN models was tried using various permutation and combinations, and it was observed that a model trained with back-propagation algorithm having 9-5-2-1 architecture is the best optimum. Flyrock were also computed from various available empirical models suggested by Lundborg. Statistical modeling has also been done to compare the prediction capability of ANN over other methods. Comparison of the results showed absolute superiority of the ANN modeling over the empirical as well as statistical models. 


\section{CONCLUSIONS}

A neural network has been found to be a good approach for the problems of rock fragmentation by blasting and it's associated environmental hazards such as fly rock, ground vibrations, air blast, dust etc. in which the mechanism is very complex, many factors influence the process and the results. Many researchers have found the accuracy of prediction, degree of robustness or fault tolerance in ANN better than empirical and other techniques because of ability of pattern recognition and continuous learning .More over, the neural network predictor takes much less time to interpret new data than existing techniques once it is properly trained.

The ability of neural networks to generalize, i.e., to produce solutions for previously unseen input data is the very basis of its predictability. Predictability of a neural network increases with the increasing number of input variables as it enhances the ability of ANN to learn and to get trained. Feed forward back-propagation algorithm has been widely used, because of its robustness in predictive problems especially in rock science and engineering.

It can be expected that with the enhancement of the training database, in terms of size as well as the diversity of the variable values, more robust neural networks can be constructed for the better representation of the physical system for complete solution of blast related hazardous effects which will later on help to propose more scientific guidelines to smoothen the blasting operations in particular as well as to sustain and protect the geo-environment at large.

\section{REFERENCES}

[1]. Adhikari, G. R. (1999) 'Studies on Flyrock at Limestone Quarries', Rock Mech Rock Engg. Vol. 32, No. 4, pp. 291301.

[2]. Ambraseys, N.R. and Hendron, A.J. (1968) 'Dynamic behaviour of rock masses', Rock Mechanics in Engineering. Practices, London: Wiley; pp. 203-7.

[3]. Bajpayee, T.S., Rehak, T.R., Mowrey, G.L., and Ingram, D.K. (2004) 'Blasting injuries in surface mining with emphasis on flyrock and blast area security', J Safety Res, Vol. 35, pp. 47- 57.

[4]. Bhandari, S. (1997) Engineering Rock Blasting Operations, Rotterdam: Balkema.

[5]. Cai, J.G. and Zhao, J. (1997) 'Use of neural networks in rock tunneling', In: Proceedings Of Computing Methods and Advances in Geomechanics, IACMAG, China, pp. 613-18.

[6]. Chakraborty, A.K., Guha, P., Chattopadhyay, B., Pal, S. and Das J. (2004) 'A Fusion Neural Network for Estimation of Blasting Vibration', In: N.R. Pal et al. (Eds.): ICONIP, (pp. 1008-1013), Berlin Heidelberg :Springer-Verlag.

[7]. Cheng, G. and Huang, S.L. (2000) 'Analysis of ground vibration caused by open pit production blast', In: Holmberg, A. (Ed.), Explosive and Blasting Technique, (pp. 63-70), Rotterdam: Balkema.
Dehghani, H. (2007) Blasting pattern design in the Gol-EGohar iron ore mine using artificial neural networks, MSc dissertation, Tarbiat Modares University, Tehran, Iran.

[8]. Demuth, H. and Beale, M. (1994), Neural Network Toolbox User's Guide, Mathworks Inc., MA.

[9]. Dowding, C.H. (1985) Blast Vibration Monitoring and Control, Englewood Cliffs, NJ: Prentice-Hall.

[10]. Dowding, C.H. (1996) Construction Vibrations, Englewood Cliffs, NJ: Prentice-Hall.

[11]. Duvall, W.I. and Fogleson, D.E. (1962) 'Review of criteria for estimating damage to residences from blasting vibration', USBM -I, p.5968.

[12]. Dysart, P.S., Pulli, J.J. (1990) 'Regional seismic event classification at the noress array: seismological measurements and the use of trained neural networks', Bull Seismol Soc Am , Vol. 80, pp.1910-33.

[13]. Finnie, G.J. (1999) 'Using neural networks to discriminate between genuine and spurious seismic events in mines', Pure Appl Geophys, Vol. 154, pp.41-56.

[14]. Fletcher, L.R.and D'Andrea, D.V. (1986) 'Control of flyrock in blasting', In: Proceedings of the $12^{\text {th }}$ Annual Conference on Explosives and Blasting Technique, International Society of Explosives Engineers, Cleveland, pp. 167-177.

[15]. Fourney, W.L., Dick, R.D., Wang, X.J. and Wei, Y. (1993) 'Fragmentation mechanisms in crater blasting', Int J Rock Mech Min Sci Geomech Abstr, Vol. 30, pp.413-429.

[16]. Freeman, A. F. and Skapura, D. M. (2002) 'Neural network - algorithms, applications \& programming technique', $5^{\text {th }}$ edn, Asia.:Pearson Education.

[17]. Gate, W.C., Ortiz B.L.T., and Florez, R.M.(2005) 'Analysis of rockfall and blasting backbreak problems', In: Proceedings Of The American Rock Mechanics Conference, 2005, Vol. 5, pp. 671-80.

[18]. Grossber, S. (1991) 'Nonlinear neural network: principles, mechanics and architecture', Neural Networks, Vol. 1, pp.17-61.

[19]. Grznar, J., Prasad, S., and Jasmine, J. (2007) 'Neural networks and organizational systems: modeling non-linear relationships', Eur J Oper Res, Vol. 181, pp.939-55.

[20]. Gupta, R.N., Pal Roy, P. and Singh, B. (1987) 'On a blast induced vibration predictor for efficient blasting', In: Proceedings of the 22nd Conference on Safety in Mines Research Institute, Beijing, China, pp. 1015-1021.

[21]. Hagan, T.N. (1973) 'Rock breakage by explosives', In: Proceedings of the national symposium on rock fragmentation, Adelaide, pp.1-17.

[22]. Hagan, T.N. (1983) 'The influence of controllable blast parameters on fragmentation and mining cost', In:Proc. $1^{\text {st }}$ Int. Symp. Rock fragmentation by blasting, Lulea, Sweden, pp. 31-33.

[23]. Harrison, J.P. and Hudson, J.A. (2000) 'Iillustrative workable examples', In: Sarkka P., Eloranta P. ( Eds.) Engineering Rock Mechanics. Part 2, Oxford: Pergamon.

[24]. Haykin, S. (1994) Neural Networks: A comprehensive Foundation, New York: Macmillan College Publishing Co. 
[25]. Hendron, A.J. (1977) 'Engineering of rock blasting on civil projects', In: Hall WJ, editor. Structural and geotechnical mechanics, a volume honoring N M Newmark, (pp. 242-77), New Jersy: Prentice Hall.

[26]. Hertz, J., Krogh A. and Palmer R. G. (1990) Introduction to Theory of Neural Computation. Addison: Wesley.

[27]. Huang, Y. and Wfinstedt, S. (1998) 'The Introduction of neural network system and its applications in rock engineering', Engg Geolog ,Vol. 49, pp.253-260.

[28]. Hudson, J.A. and Hudson, J.L. (1997) 'Rock mechanics and the Internet', Int J Rock Mech Min Sci, Vol. 34, No. 3-4, pp. 603.

[29]. Hornik, K. (1991) Approximation capabilities of multi layer feed forward networks, Neural Networks, Vol. 4, No. 2, pp.251-257.

[30]. Indian Standard (1973) Criteria for safety and design of structures subjected to under ground blast. ISI., IS-6922.

[31]. ISRM (1992) 'Suggested method for blast vibration monitoring', Int J Rock Mech Min Sci Geomech Abstr, Vol, 29, No. 2 pp.145-146.

[32]. Institute of Makers of Explosives (IME) (1997) 'Glossary of commercial explosives industry terms',. Safety publication, No. 12, Institute of Makers of Explosives, Washington, DC, p. 16.

[33]. Jimeno, C.L., Jimeno, E.L., and Carcedo, F.J.A. (1995) Drilling and blasting of rocks. Rotterdam: Balkema..

[34]. Jing, L. and Hudson, J.A. (2002) 'Numerical methods in rock mechanics', Int J Rock Mech Min Sci, Vol. 39, pp. 409427.

[35]. Jing, L. (2003) 'A review of techniques, advances and outstanding issues in numerical modelling for rock mechanics and rock engineering', Int J Rock Mech Min Sci, Vol. 40, pp. 283-353

[36]. Jong, Y.H. and Lee, C.I.(2004) 'Influence of geological conditions on the powder factor for tunnel blasting', Int $\mathbf{J}$ Rock Mech Min Sci, Vol. 41, No. Suppl. 1, pp. 2B 12 1-7

[37]. Jong, Y. and Lee, C. (2002) 'Application of neural networks to prediction of powder factor and peak particle velocity in tunnel blasting', In:Proceedings of the Annual Conference on Explosives and Blasting Technique, Volume 2, pp. 67-76.

[38]. Karami, A.R., Mansouri, H., Farsangi, M.A.E., Nezamabadi, H., (2006) 'Backbreak prediction due to bench blasting: An artificial neural network approach', J Mines, Metals and Fuels, Vol. 54, No.12, pp. 418-420.

[39]. Kecojevic, V. and Radomsky, M. (2005) 'Flyrock phenomena and area security in blasting-related accidents', Safety Sci, Vol. 43, pp. 739-750.

[40]. Khandelwal, M. and Singh, T.N. (2002) 'Prediction of waste dump stability by an intelligent approach'. In: national symposium on new equipment-new technology, management and safety, ENTMS, Bhubaneshwar; pp. 38-45.

[41]. Khandelwal, M. and Singh, T.N. (2005) 'Prediction of blast induced air overpressure in opencast mine', Noise Vibrat. Worldwide, Vol. 36, No. 2, pp. 7-16.
[42] Khandelwal, M. and Singh, T.N. (2006) 'Prediction of blast induced ground vibrations and frequency in opencast mine: a neural network approach', J Sound Vibrat, Vol. 289, pp.711-25.

[43].Khandelwal, M. and Singh, T.N. (2007) 'Evaluation of blast-induced ground vibration predictors', Soil Dynam Earthq Engg, Vol. 27, pp.116-25.

[44]. Kim, C.Y., Bae, G.J., Hong, S.W., Park, C.H., Moon, H.K., Shin, H.S. (2001) 'Neural network based prediction of ground surface settlements due to tunneling', Comput Geotech, Vol. 28, pp.517-47.

[45]. Konya, C.J. (2003) Rock Blasting and overbreak control, $2^{\text {nd }}$ ed. USA: National Highway Institute; FHWA-HI-92-001.

[46]. Konya, C.J. and Walter, E.J. (2000) Surface blast design, USA: Prentice-Hill; 2000.

[47]. Kosko, B. (1994) Neural networks and fuzzy systems: a dynamical systems approach to machine intelligence, New Delhi: Prentice Hall of India.

[48]. Kuzu, C., Fisne, A. and Ercelebi, S.G.(2009) 'Operational and geological parameters in the assessing blast induced airblast-overpressure in quarries', Appl Acoustics, Vol 70, pp.404-411.

[49]. Langefors, U., Kihlstrom, B., and Westerberg, H. (1958) Ground vibrations in blasting, Water Power.

[50]. Langefors, U. and Kihlstrom, B. (1978) The modern techniques of rock blasting. third ed.. New York: Wiley.

[51]. Lawrence, J.D., William, H.L., Janet, S.S. (2002) 'Environmentalism and natural aggregate mining', Nat Resour Res, Vol. 11, No. 1, pp.19-28.

[52]. Leu, S.S. , Lin, S.F., Chen, C.K. and Wang, S.W.(1998) 'Analysis of powder factors for tunnel blasting using neural networks', Fragblast Vol. 2, No. 4, pp. 433-448.

[53]. Li, X., Wang, X., Dong, Y., Ge, Q., and Li Q. (2006) 'An Expert System Based on BP Neural Networks for Presplitting Blasting Design', Lecture Notes In Computer Science, (pp.1236-40) Berlin Heidelberg : Springer.

[54]. Lianjon, G., Guojian, Z., and Yingxian, T. (2002) 'Rock fragmentation by blasting' In: Proc. of 7th Int.Symp., China Society of Engineering Blasting, Beijing, China, August 2002, pp.302-305.

[55]. Lippman R. P. (1987) 'Introduction to computing with neural nets', IEEE ASSP Magazine, pp.4-22.

[56]. Lu, Y. (2005) 'Underground blast induced ground shock and its modeling using artificial neural network', Comput Geotech, Vol. 32, pp.164-178.

[57]. MacKay, D.J.C.(1992) 'Bayesian interpolation', Neural Computation, Vol. 4, No. 3, pp. 415-447.

[58]. Madhusudhan, N., Singh, T. N. and Singh P. K.(2001) 'Application of Artificial Neural Networks to Predict Peak Particle Velocity', In: Proc. Workshop on Computer lication and advancements in explosive and blasting technologies, CMRI, Dhanbad, India, 5-9 November, pp.45-55.

[59]. Maity, D. and Saha, A. (2004) 'Damage assessment in structure from changes in static parameters using neural networks', Sadhana, Vol. 29, pp.315-27. 
[60]. Maulenkamp, F. and Grima, M.A. (1999) 'Application of neural networks for the prediction of the unconfined compressive strength (UCS) from Equotip Hardness', Int J Rock Mech Min Sci, Vol. 36, pp.29-39.

[61].McKenzie, C. (1990) 'Quarry blast monitoring technical and environmental perspective', Quarry Management , pp. 2329.

[62]. McMahon, G.W.(1993) 'Intermediate-scale underground magazine explosion tests-decoupled ground motion experiments', Vicksburg MS 39180-0631: US Army Engineer Waterways Experiment Station..

[63]. Moghadam, M.J., Farsangi, M.A.E., Mansouri, H., Nezamabadi, H.(2006) 'Muck-pile fragmentation prediction using artificial neural networks', J Mines, Metals and Fuels, Vol. 54, No.12, pp. 421-423

[64]. Mohamed, M.T. (2009) 'Artificial neural network for prediction and control of blasting vibrations in Assiut (Egypt) limestone quarry', Int J Rock Mech Min Sci, Vol. 46, pp. 42643.

[65]. Monjezi M., Singh, T.N., Khandelwal, M., Sinha, S., Singh, V., Hosseini, I. (2006a) 'Prediction and analysis of blast parameters using artificial neural network', Noise Vibrat Worldwide, Vol. 37, pp.8-16.

[66]. Monjezi, M., Yazdian, A.and Hesami, S.M. (2006b) 'Use of back propagation neural network to estimate burden in tunnel blasting', J Mines, Metals and Fuels, Vol. 54, pp.4249.

[67]. Monjezi, M., Dehghan, H.and Samimi Namin, F. (2007) 'Application of TOPSIS method in controlling fly rock in blasting operations', In: Proceedings of the seventh international science conference SGEM. Sofia: Bulgaria; pp. $41-9$.

[68]. Monjezi, M.and Dehghani, H. (2008) 'Evaluation of effect of blasting pattern parameters on back break using neural networks', Int J Rock Mech Min Sci, Vol. 45, pp. 1446-1453.

[69]. Murrell, D.W.and Joachim, C.E. (1996) 'The 1996 Singapore ground shock test.' Vicksburg, MS: Waterways Experiment Station (WES), Dept. of Army..

[70]. Musil, M. and Plesinger A. (1996) 'Discrimination between local micro earth- quakes and quarry blasts by multilayer perceptrons and Kohonen maps', Bull Seismol Soc Am, Vol. 86, pp.1077-90.

[71]. Neaupane, K,M, and Achet, S.H. (2005) 'Use of backpropagation neural network for landslide monitoring: a case study in the higher Himalaya.', Engg Geolog, Vol. 74, pp.213-26.

[72]. Neaupane, K.M. and Adhikari, N.R.(2006) 'Prediction of tunneling-induced ground movement with the multi-layer perceptron',. Int J Tunnel Undergr Space Technol, Vol. 21, pp.151-9.

[73]. Oriard, L. L. (2002) Explosive Engineering, Construction Vibrations And Geotechnology, Cleveland: OH, International Society of Explosive Engineering.
[74]. Pal Roy, P. (1993), 'Putting Ground Vibration Prediction into Practices', Colliery Guardian.U.K., Vol. 241, No. 2, pp.63-67.

[75]. Pal Roy, P. (2005) Rock blasting effects and operations, Rotterdam: Balkema, pp. 223-40.

[76]. Persson, P., Holmberg, R., and Lee, J. (1984) Rock Blasting and Explosives Engineering, New York: CRC Press.

[77]. Perrson, P. A. (1997) 'The relationship between strain energy, rock damage, fragmentation and throw in rock blasting', Int. J. Blasting Fragmentation, Vol. 1, pp. 99-109.

[78]. Rai, R., Maheshwari, M., Sohane, N. and Ranjan, A. (2004) 'Prediction of Maximum Safe Charge per Delay by Application of Artificial Neural Network', In: National Seminar On Rock Fragmentation, 23-24 January 2004, B.H.U, Varanasi, India.

[79]. Raina, A.K., Haldar, A., Chakraborty, A.K., Choudhury, P.B. and Ramulu, M. (2004) 'Human response to blast induced vibration and air overpressure: an Indian scenario', Bull Engg Geolog Environ, Vol. 63, pp.209-14.

[80]. Ramchandar, K. and Singh, T. N. (2001) 'A computational approach for prediction of rock fragmentation', Min.Engg. J., Vol. 3, pp.16-25.

[81]. Rehak, T.R., Bajpayee, T.S., Mowrey, G.L.and Ingram, D.K. (2001) 'Flyrock issues in blasting', In: Proceedings of the 27th Annual Conference on Explosives and Blasting Technique, vol. I. International Society of Explosives Engineers, Cleveland, pp. 165-175.

[82]. Remennikov, A.M. and Mendis, P.A. (2006) 'Prediction of airblast loads in complex environments using artificial neural networks', WIT Trans on the Built Environ, Volume 87, pp. 269-278.

[83]. Rudajev, V., Ciz, R. (1999) 'Estimation of mining tremor occurrence by using neural networks', Pure Appl Geophys, Vol. 154, pp.:57-72.

[84]. Rumelhart, D. E. and McClelland, J. L. (Eds) (1986) Parallel Distributed Processing, Cambridge MA: MIT Press.

[85]. Sawmliana, C., Pal Roy, P., Singh, R. K. and Singh, T. N. (2007) 'Blast induced air overpressure and its prediction using artificial neural network', Min Technol. (Trans. Inst. Min. Metall. A), Vol. 116, No. 2, A41-A48.

[86]. Shan, R., Wang, X., Gao, W., Cheng, X., Wang, J. and Chen, M. (2007) 'Application research of artificial neural networks to tunnel blasting', Chinese J Rock Mech and Engg. Vol.26, Issue Suppl. 1, pp. 3322-3328.

[87]. Shea, C.W. and Clark, D. (1998) 'Avoiding tragedy: lessons to be learned from a flyrock fatality', Coal Age, Vol.103, No. 2, pp.51-54.

[88]. Simpson, P.K. (1990) Artificial neural systemfoundation, paradigm, application and implementations. New York: Pergamon Press.

[89]. Siskind, D.E. and Kopp, J.W. (1995) 'Blasting accidents in mines: a 16 year summary', In: Proceedings of the $21^{\mathrm{st}}$ Annual Conference on Explosives and Blasting Technique, International Society of Explosives Engineers, Cleveland, pp. 224-239. 
[90]. Singh, D.P. and Sastry, V.R. (1986) 'Rock fragmentation by blasting influence of joint filling material', J Explos Engg, pp.18-27.

[91]. Singh, D.P., Singh, T.N. and Goyal, M. (1994a) 'Ground vibration due to blasting and its effect', In: Pradhan, G.K., Hota, J..K, editors., ENVIROMIN, Bhubaneshwar, India, pp. 287-93.

[92]. Singh, T. N., Singh, A. and Singh, C. S. (1994b) 'Prediction of ground vibration induced by blasting', Ind. Min. Eng. J., Vol. 33, pp.31-34.

[93]. Singh, T. N. (1995a) 'A study of blast induced ground vibration at Dharapani Magnesite Mine, Pitthoragarh Himalaya, India', In: Proceedings of the third international symposium on headwater control, New Delhi, pp. 183-8.

[94]. Singh, T. N. (1995b) 'Prediction of ground vibration to save nearby structures due to blasting', Indian Cement Industry Desk Book, Commercial, pp.169-175.

[95]. Singh, T.N. (2004) 'Artificial neural network approach for prediction and control of ground vibrations in mines', Min Technol, Sec A, Vol. 113, No. 4, pp.:251-6.

[96]. Singh, T. N., Kanchan, R., Saigal, K. and Verma, A.K. (2004a) 'Prediction of P-wave velocity and anisotropic properties of rock using Artificial Neural Networks technique', J Sci Ind Res, Vol. 63, pp.32-8.

[97]. Singh, T. N., Kanchan, R., and Verma, A.K. (2004b) 'Prediction of blast induced ground vibration and frequency using an artificial intelligence technique', Noise Vibrat. Worldwide, Vol. 35, No.11, pp.7-14.

[98]. Singh, T. N. and Singh, V. (2005) 'An intelligent approach to prediction and control ground vibration in mines', Geotech Geo. Eng J, Vol. 23, pp.249-262.

[99]. Singh, T. N., Kanchan, R., Verma, A.K. and Saigal, K. (2005) 'A comparative study of ANN and Neuro-fuzzy for the prediction of dynamic constant of rockmass', J. Earth Syst. Sci., Vol. 114, No. 1, pp. 75-86.

[100]. Singh, V.K., Singh, D.and Singh, T.N. (2001) 'Prediction of strength properties of some schistose rock', Int J Rock Mech Min Sci, Vol. 38, No. 2, pp.269-84.

[101]. Tang, H., Shi, Y., Li, H., Li, J., Wang, X., and Jiang, P. (2007) 'Prediction of peak velocity of blasting vibration based on neural network', Chinese J Rock Mech and Engg, Volume 26, Issue Suppl. 1, pp. 3533-3539.

[102]. Tawadrou, A. S. and. Katsabani, P. D. (2005) 'Prediction of surface blast patterns in limestone quarries using artificial neural networks', Fragblast, Volume 9, No. 4 pp. $233-242$.

[103]. Tawadrous, A.S. (2006) 'Evaluation of artificial neural networks as a reliable tool in blast design', Int Soc Explos Engg Vol. 1, pp.1-12.

[104]. Tawadrous, A.S. and Katsabanis, P.D. (2006) 'Prediction of surface crown pillar stability using artificial neural networks', Int J Num Anal Methods Geomech, Vol.31, pp.917-31.

[105]. Werbos, P.J. (1974) Beyond Regression: New Tools For Prediction And Analysis In The Behavioral Science, Ph. D. Thesis, Harvard University, Cambridge, M.A..
[106]. Wharton, R.K., Formby, S.A., and Merrifield, R. (2000) 'Airblast TNT equivalence for a range of commercial blasting explosives', J Hazard Mater, Vol. A79, pp.31-9.

[107]. Wiss, J.F. (1981) 'Construction vibrations, state of the art', J Geotech Engg, ASCE Vol.107, No. 2, pp.167-81.

[108]. Wiss, J.F. and Linehan, P.W. (1978) 'Control of vibration and air noise from surface coal mines-III'. Report no. OFR 103 (3) - 79, Bureau of Mines, US, pp. 623.

[109]. Workman, J. L.and Calder, P. N. (1994) 'Flyrock prediction and control in surface mine blasting', In: Proceedings of $20^{\text {th }}$ Conf. on Explosives and Blasting Technique, Austin, Texas, pp. 59-74.

[110]. Yang Y. and Zhang Q. (1997a) 'Analysis for the results of point load testing with artificial neural network.', In: Proceedings of Computing Methods and Advances In Geomechanics, IACMAG, China, pp. 607-12.

[111]. Yang Y. and Zhang Q. (1997b) 'A hierarchical analysis for rock engineering using artificial neural networks', Rock Mech Rock Engg, Vol. 30, pp.207-22.

[112]. Yang, C. and Feng, X. (2004) 'Assessment of blast vibration response of structures around mines using evolutionary-neural approach', In : International Symposium on Safety Science and Technology, Issue PART A, pp. 797802.

[113]. Zhu, H.B. and Wu, L. (2005) 'Application of gray correlation analysis and artificial neural network in rock mass blasting', J Coal Sci Engg, Vol. 11, No.1, pp. 44-47.

[114]. M. Monjezi, Amir Bahrami, Ali Yazdian Varjani, Ahmad Reza Sayadi, (2011) Prediction and controlling of flyrock in blasting operation using artificial Neural network, Arabian Journal of Geosciences, Volume 4, Issue 3-4, pp 421425

[115]. Manoj Khandelwal, (2012) Application of an Expert System for the Assessment of Blast,Vibration, Geotechnical and Geological Engineering, Volume 30, Issue 1, pp 205-217

[116]. Masoud Monjezi, Mahdi Hasanipanah, Manoj Khandelwal, (2013), Evaluation and prediction of blastinduced ground vibration at Shur River Dam, Iran, by artificial neural network, Neural Computing and Applications, Volume 22, Issue 7-8, pp 1637-1643

[117]. M. Monjezi , M. Ghafurikalajahi, A. Bahrami, (2011), Prediction of blast-induced ground vibration using artificial neural networks, Tunneling and Underground Space Technology, Volume 46, Issue 7, , Pages 1214-1222

[118]. Kazim Görgülü, Ercan Arpaz, Ahmet Demirci, Arzu Koçaslan, M. Kürsat Dilmaç, A. Gürkan Yüksek, (2013), Investigation of blast-induced ground vibrations in the Tülü boron open pit mine, Bulletin of Engineering Geology and the Environment, Volume 72, Issue 3-4, pp 555-564

[119]. Bao-fu Duan, Jun-meng Li, Meng Zhang, (2010), BP neural network model on the forecast for blasting vibrating parameters in the course of hole-by-hole detonation,Journal of Coal Science and Engineering (China), Volume 16, Issue 3, pp 249-255

[120]. D. Jahed Armaghani, M. Hajihassani, E. Tonnizam Mohamad, A. Marto, S. A. Noorani,(2013), Blasting-induced 
flyrock and ground vibration prediction through an expert artificial neural network based on particle swarm optimization, Arabian Journal of Geosciences

[121]. M. Monjezi, H. Amiri, A. Farrokhi, K. Goshtasbi, (2012), Prediction of Rock Fragmentation Due to Blasting in Sarcheshmeh Copper Mine Using Artificial Neural Networks, Geotechnical and Geological Engineering, Volume 28, Issue 4, pp 423-430

[122]. A. Bahrami, M. Monjezi, K. Goshtasbi, A. Ghazvinian, (2011), Prediction of rock fragmentation due to blasting using artificial neural network, Engineering with Computers, Volume 27, Issue 2, pp 177-181

[123]. M. Monjezi, S. M. Hashemi Rizi, V. Johari Majd, Manoj Khandelwal, (2013), Artificial Neural Network as a Tool for Backbreak Prediction, Geotechnical and Geological Engineering

[124]. Mehmet Sari, Ebrahim Ghasemi, Mohammad Ataei, (2013), Stochastic Modeling Approach for the Evaluation of Backbreak due to Blasting Operations in Open Pit Mines, Rock Mechanics and Rock Engineering

[125]. Ebrahim Ghaesemi, Hasemi Amini, Mohammad Ataei, Reza Khalokakaei, (2012), Application of artificial intelligence techniques for predicting the flyrock distance caused by blasting operation, Arabian Journal of Geosciences [126]. D. Jahed Armaghami, M. Hajihassani, E. Tonnizam Mohammad, A. marto, S.A.Noorani, (2013), Blasting-induced flyrock and ground vibration prediction through an expert artificial neural network based on particle swarm optimization, Arabian Journal of Geosciences

[127]. M. Monjezi, A. Mehrdanesh, A. Malek, Manoj Khandelwal, (2013), Evaluation of effect of blast design parameters on flyrock using artificial neural networks, Neural Computing and Applications, Volume 23, Issue 2, pp 349-356

[128]. F. Faramarzi, H. Mansouri n, M.A. Ebrahimi Farsangi, (2013), Rock engineering systems based model to predict rock fragmentation by blasting, International Journal of Rock Mechanics \& Mining Sciences, vol 60 (2013) pg. no. 82-94 